\title{
Late radiation therapy brain abnormalities that mimic leukoencephalopathy with anterior temporal lobe cysts
}

Alterações encefálicas tardias pós radioterapia mimetizando leucoencefalopatia com cistos temporais anteriores

Marcos Rosa Júnior ${ }^{1,2}$, Antônio José da Rocha ${ }^{3}$

A 43-year-old man who had been treated for a craniopharyngioma with surgery and radiotherapy (33 years ago) was referred for evaluation of a sudden hemiparesis. Neuroimaging documented a brainstem cavernoma associated with basal ganglia calcifications and white matter hyperintensity near anterior temporal lobe cysts (Figures 1 and 2).

Late brain abnormalities are often observed after radiotherapy for childhood intracranial tumors.
Microbleeds and cavernomas are well recognized in these cases. However, bilateral anterior temporal lobe cysts are uncommon, and it is crucial to recognize these to avoid misdiagnoses, particularly when they are associated with white matter abnormalities. Differential diagnoses include hereditary disorders, infectious diseases, and dilated perivascular spaces ${ }^{1,2,3,4}$.
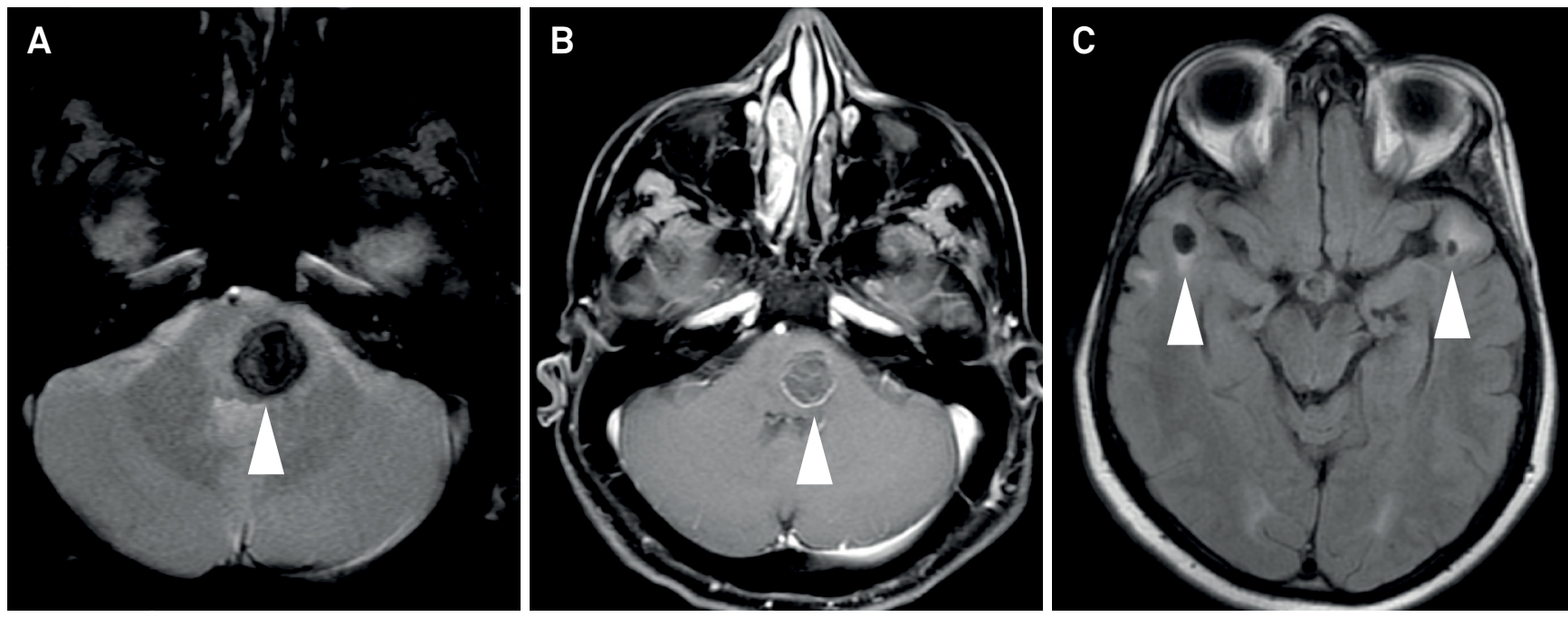

Figure 1. Axial GRE (A) and T1 GD (B) showed a focal hemorrhage compatible with a radiation-induced cavernoma in the brainstem. Axial FLAIR (C) showed white matter hyperintensity around anterior temporal lobe cysts.

${ }^{1}$ Universidade Federal do Espírito Santo, Departamento de Radiologia, Vitória ES, Brasil;

2BRAEN, Laboratório de Pesquisa em Neurorradiologia, Vitória ES, Brasil;

${ }^{3}$ Santa Casa de Misericórdia de São Paulo, Seção de Neurorradiologia, São Paulo SP, Brasil.

Correspondence: Marcos Rosa Júnior; Universidade Federal do Espírito Santo - UFES, Centro de Ciências da Saúde; Av Marechal Campos, 1468 ; $29043-900$ Vitória ES, Brasil; E-mail: marcosrosajr@hotmail.com

Conflict of interest: There is no conflict of interest to declare.

Received 18 August 2016; Accepted 31 December 2016. 

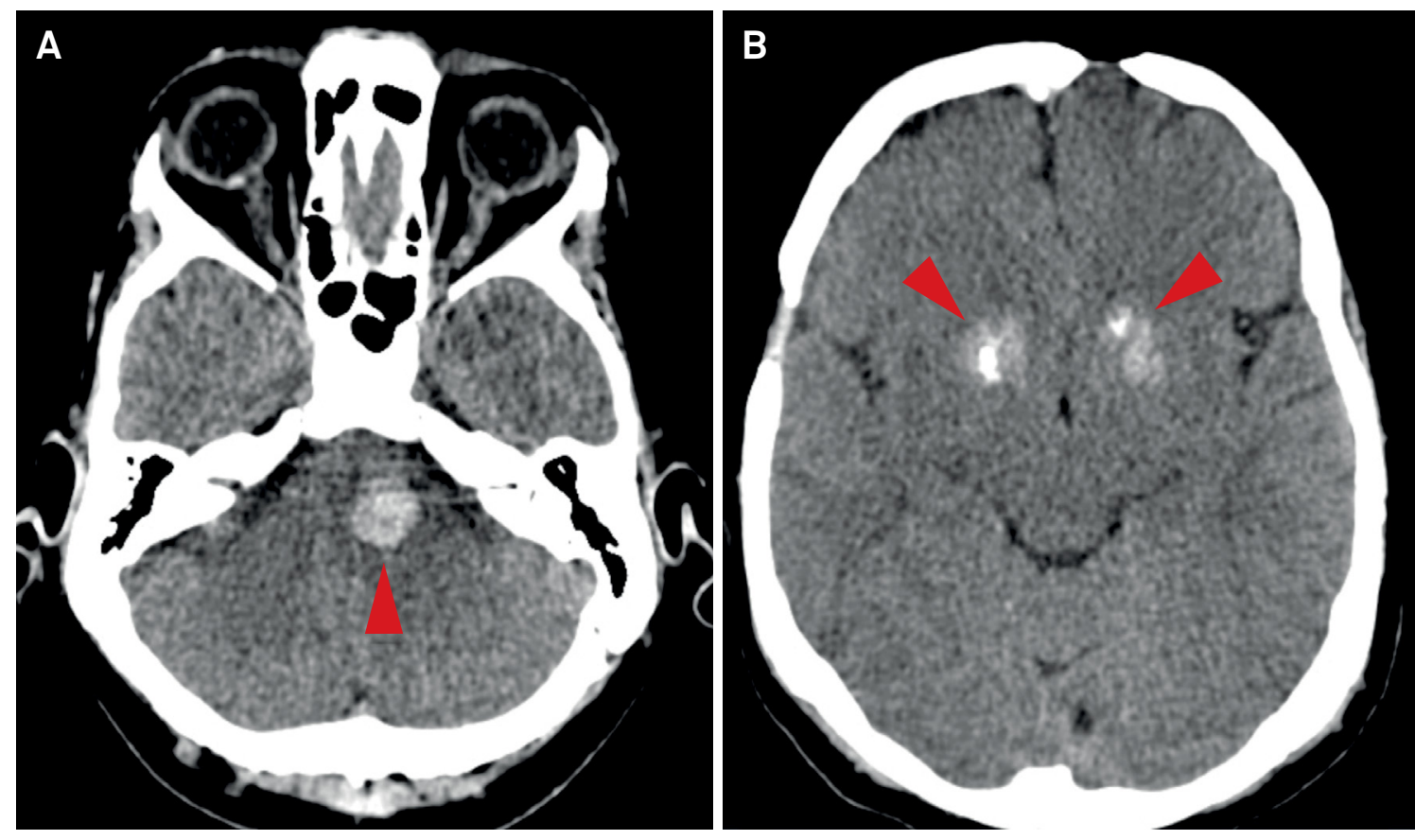

Figure 2. Axial non-contrast CT confirmed a hemorrhagic lesion in the brainstem (A) and basal ganglia calcifications (B).

\section{References}

1. Nunes RH, Pacheco FT, Rocha AJ. Magnetic resonance imaging of anterior temporal lobe cysts in children: discriminating special imaging features in a particular group of diseases. Neuroradiology. 2014;56(7):569-77. https://doi.org/10.1007/s00234-014-1356-9

2. Cross NE, Glantz MJ. Neurologic complications of radiation therapy. Neurol Clin N Am. 2003;21(1):249-77. https://doi.org/10.1016/S0733-8619(02)00031-2
3. Osborn AG, Preece MT. Intracranial cysts: radiologic-pathologic correlation and imaging approach. Radiology. 2006;239(3):650-4. https://doi.org/10.1148/radiol.2393050823

4. Rawal S, Croul SE, Willinsky RA, Tymianski M, Krings T. Subcortical cystic lesions within the anterior superior temporal gyrus: a newly recognized characteristic location for dilated perivascular spaces. AJNR Am J Neuroradiol. 2014;35(2):317-22. https://doi.org/10.3174/ajnr.A3669 